\title{
The Effect of Cognitive Behavioral Therapy and Changes of Depressive Symptoms among Thai Adult HIV-Infected Patients
}

\author{
Isareethika Jayasvasti ${ }^{1}$, Narin Hiransuthikul ${ }^{1}$, Nuttorn Pityaratstian ${ }^{2}$, Vitool Lohsoonthorn ${ }^{1}$, \\ Buranee Kanchanatawan ${ }^{2}$, Boonruang Triruangworawat ${ }^{3}$
}

${ }^{1}$ Department of Preventive and Social Medicine, Faculty of Medicine, Chulalongkorn University, Bangkok, Thailand; ${ }^{2}$ Department of Psychiatry, Faculty of Medicine, Chulalongkorn University, Bangkok, Thailand; ${ }^{3}$ Department of Health Service Support, Ministry of Public Health, Bangkok, Thailand.

Email: nhiransu@yahoo.com, nhiransu@gmail.com

Received March 17 ${ }^{\text {th }}, 2011$; Revised April 12 ${ }^{\text {th }}, 2011$; Accepted April 25 $5^{\text {th }}, 2011$.

\begin{abstract}
Background: In Thailand, the therapeutic effect of cognitive behavioral therapy (CBT) for depression among adult $H I V$-infected patients has been limitedly studied. Objectives: To determine the association of CBT and changes of depression both immediately post treatment and at 3-month post-treatment. Materials and Methods: A prospective cohort study was conducted at the University Hospital in Thailand. Forty and eighty HIV-infected adults who voluntarily received and did not receive CBT were recruited from the immunology clinic and sexually transmitted diseases clinic between September 2010 and February 2011. Sociodemographic characteristics and medical histories of the participants were collected. A standard Thai Depression Inventory (TDI) was used for evaluation of depressive symptoms. TDI score of 21 or above was interpreted as depression. Other questionnaires included a Montreal Cognitive Assessment questionnaire, standard questionnaire for evaluating life stress event and questionnaire for HIV social support. Results: The mean ages of participants were 44.8 and 43.4 years in the CBT and non-CBT groups respectively. In both group, about half of the subjects were females. Life stress event score in CBT group was significantly higher than the non-CBT group $(p<0.01)$. At baseline, the mean TDI scores of the CBT group and non-CBT group were 26.7 and 25.3 respectively. After adjustment for age, gender, social support, life stress event and current opportunistic infection; the mean changes of TDI scores in the CBT group were significantly higher than the non-CBT group both immediately [12.13 (95\% CI, 10.00 - 14.26)] ( $p$ 0.001) and at 3-month post-treatment [15.94 (95\% CI, $13.69-18.18)](p<0.001)$. Conclusions: CBT is beneficial for treatment of depression among adult HIV-infected patients in Thailand. The beneficial effect of CBT was not only immediate but also sustained at 3-month post-treatment.
\end{abstract}

Keywords: Cognitive Behavioral Therapy (CBT), HIV/AIDS, Depression

\section{Introduction}

By the year 2020, World Health Organization has predicted that depression will be the leading cause of worldwide disability [1]. Globally, several studies have shown that the prevalence of depression among human immunodeficiency virus (HIV)-infected patients and AIDS was higher than normal population with a prevalence of about 15 - 30 percent [2-5]. HIV infection affects all aspects of a patient's life and results in physical, psychological, social, and spiritual adaptation. Mental health problems among individuals with HIV infection include grief, stigmatization, fear of reaction from others, uncertainly about the future, and changes in identity as well as psychological disorders, especially depression [6,7]. HIV disease is also influenced by one's coping style, social support, and other life stress [6,8,9]. Several studies have shown that depression was significantly associated with poor adherence to highly active antiretroviral therapy (HAART) [3,10-14]. This resulted in drug resistance mutation and treatment failure [8] which increased patients' health care costs $[3,15]$ and affected their quality of life as well as health outcomes[16,17]. Similarly, depression has been related to faster increase in plasma HIV viral load, more rapid decline in CD4+T lymphocyte cells count [18] and progression to AIDS, 


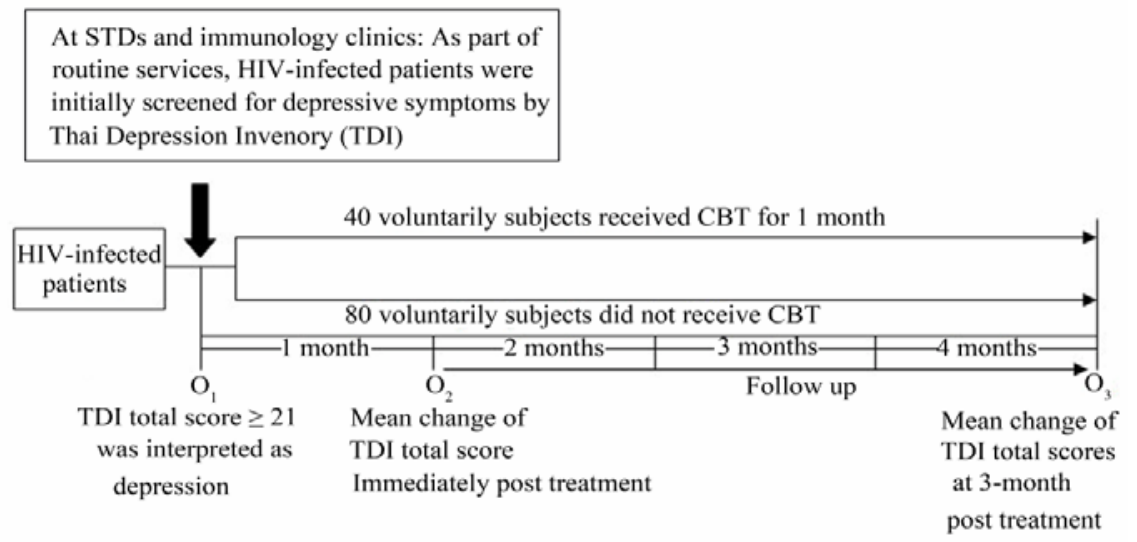

Figure 1. The process of study.

and increased mortality [19].

Psychotherapy has been shown to promote adaptation to neuropsychiatric and psychosocial problem in HIV-infected patients [6]. Specific individual and group psychotherapy are both effective for reducing depressive symptoms in people with HIV [20,21]. Cognitive behavioral therapy (CBT) is a psychotherapeutic method that has been shown to be effective for treatment of depression [3,22-25] and also useful for HIV-infected patients [26]. It is a structured, goal-oriented therapy and based on two way collaboration between therapist and client. CBT is designed to be as short term as possible [27] and focus on identifying automatic thoughts, modifying the dysfunctional thoughts and promoting more realistic adaptive patterns of thinking and behavior that may contribute to or prolong an episode of depression $[28,29]$. In Thailand, there were few studies addressing CBT for treatment of HIV-infected patients with depression. However, they did not control for confounding effects and were not designed to examine the sustainability of CBT on treatment of depression. The objectives of this study were to determine the association of CBT and change of depression among Thai adult HIV-infected patients both immediately and at 3-month post-treatment as well as to examine whether improvement of depression in those who completed CBT was sustained during follow-up.

\section{Materials and Methods}

This cohort study was conducted at King Chulalongkorn Memorial Hospital (KCMH), Bangkok, Thailand. $\mathrm{KCMH}$ is a 2000-bed public medical school hospital which provides medical services mainly for lower and middle income population. Participants were recruited from the immunology clinic and sexual transmitted diseases clinic between September 2010 and February 2011.

At both clinics, CBT has been a routine service for treatment of HIV-infected clients with depression. HIVinfected clients were informed about the detail of the study by professional nurses of each clinic. Those who agreed to participate in the study were initially screened for depression using the self-reported depression inventory (Thai Depression Inventory; TDI) [30]. Individuals with depression were asked whether they would like to receive CBT by the expert or not. Those who agreed were sent to CBT expert. For CBT, there were eight therapeutic sessions (two sessions per week) in one month period. The process of conducting the study was summarized in Figure 1. Inclusion criteria were HIV-infected individual with age above 18 years, educational level at least primary school and having TDI score of at least 21. Exclusion criteria were previous diagnosis of other major mental health illness including psychotic disorder, bipolar disorder, organic brain syndrome, active use of substance or other, axis I psychiatric conditions that would interfere with the ability to participate in group psychotherapy and subjects whose treatment with psychotropic agents were not stable. Data were collected by a set of questionnaires that consisted of 5 parts. The first part was a Case Record Form (CRF) used for collecting sociodemographic characteristics and medical history of participants. The second part was a TDI, a culturally appropriate instrument for measuring the severity of depression with good reliability (Cronbach's alpha $=0.86$ ) and for the validity of this tool, it was compared with The Hamilton Rating Scale for concurrent validity. The result showed that the TDI well reflected the severity of depression (The Pearson product moment correlation was 0.72). This questionnaire has 20 items. TDI score was a subjective oriented rating scale with range of score 0 to 60 . TDI score of 21 or above was interpreted as depression, higher scores reflecting greater depression [30]. Assessment of depression by TDI was repeated both among participants who did and did not 
receive CBT immediately and at 3-month post-treatment. The third part was the Montreal Cognitive Assessment (MOCA) questionnaire with aim to detect mild cognitive impairment (MCI) of the subjects. Scores below 26 indicated MCI. The sensitivity and specificity of MOCA for MCI is 0.90 and 0.87 respectively [31]. The fourth part was the 43 item-questionnaire, adapted from Holmes and Rahe stress scale, to assess life stress event within the past 1 year of an individual's life according to life stress event. It had very good reliability (Cronbach's alpha = 0.99) [32]. The final part was the HIV social support questionnaire adapted from patients' report assessment of living with HIV/AIDS in resource-constrained settings. It had good reliability (Cronbach's alpha $=0.85$ ). The higher score indicated higher social support [13].

\section{Statistical Analysis}

Sample size calculation for cohort study was done. We used the parameter from the study of the effective of CBT and depression among HIV-infected patients by Safren et al. [33], which found that a mean difference of depression score between CBT and non CBT group was 7 and the variance of the mean difference was 9.9. We used the alpha of 0.05 , power of 0.80 , the ratio of the CBT versus non-CBT group was 1:2 to obtain the adequate sample size in both CBT and non-CBT group [34]. The calculated sample size of CBT and non-CBT groups were 40 and 80 respectively. Sociodemographic characteristics and clinical parameter were described using descriptive statistics. The univariate analysis for association between CBT and depression were done by student's t-test. To compare baseline characteristics between CBT versus non-CBT group, we used student's t-test for continuous variables and chi-square test or Fisher exact test for categorical variables. The variables between CBT versus non-CBT group that were not comparable at baseline and the variables associated with depression from literature review were selected for multiple linear regression to look for adjusted association between CBT and depression. A p-value of less than 0.05 was considered statistically significant.

\section{Results}

The calculated number of participants in CBT and non-CBT groups was 40 and 80 respectively. At baseline, no statistically significant differences were observed between CBT and non-CBT groups regarding to sociodemographic and clinical characteristics (Table 1). The psychological factors in each group were shown in Table 2. We found that there were statistically significant higher score of life stress event in the CBT group ( $<$ 0.05).

TDI scores in each group at baseline, immediately and 3-month post-treatment were demonstrated in Table 3 and Figure 2. The retention rate in CBT group at final evaluation was $95 \%$. Two subjects in the CBT group and ten in the non-CBT group lost to follow-up at 3-month follow-up. At baseline, no statistically significant difference in mean TDI score was observed between CBT and non-CBT group. By univariate analysis, the CBT group had statistically significant higher mean changes of TDI score both immediately and at 3-month post-treatment (p

Table 1. Demographic and clinical characteristics of study population $(\mathrm{N}=120)$.

\begin{tabular}{|c|c|c|c|}
\hline Characteristics & $\begin{array}{l}\text { CBT group } \\
(\mathrm{n}=40)\end{array}$ & $\begin{array}{l}\text { Non-CBT group } \\
(\mathrm{n}=80)\end{array}$ & p-value ${ }^{\dagger}$ \\
\hline Mean age (SD) & $44.8(12.01)$ & $43.4(8.84)$ & 0.46 \\
\hline Female (\%) & $23(57.5)$ & $40(50.0)$ & 0.44 \\
\hline Heterosexual HIV transmission (\%) & $32(80.0)$ & $68(85.0)$ & 0.54 \\
\hline Education (\%) & & & 0.40 \\
\hline Primary school & $17(42.5)$ & 25 (31.3) & \\
\hline Secondary school & $13(32.5)$ & $24(30.0)$ & \\
\hline Diploma & $6(15.0)$ & $11(13.8)$ & \\
\hline Bachelor's degree or higher & $4(10.0)$ & $20(25.0)$ & \\
\hline Couple marital status (\%) & $17(42.5)$ & $35(43.8)$ & 0.96 \\
\hline Others have known HIV status (\%) & $29(72.5)$ & $61(76.3)$ & 0.65 \\
\hline Having opportunistic infection (\%) & 15 (37.5) & $27(33.8)$ & 0.69 \\
\hline Having others physical illness (\%) & $20(50.0)$ & $48(60.0)$ & 0.30 \\
\hline Using hypnotic drug (\%) & $13(32.5)$ & $21(26.3)$ & 0.47 \\
\hline On current HAART (\%) & 35 (87.5) & $72(90.0)$ & 0.68 \\
\hline Taking efavirenz (\%) & $14(35.0)$ & 29 (36.3) & 0.89 \\
\hline Mean time(year)since HIV diagnosis (SD) & $7.6(5.13)$ & $8.7(5.72)$ & 0.27 \\
\hline Mean time(year)since start HAART (SD) & $5.1(4.33)$ & $5.9(4.84)$ & 0.37 \\
\hline Median current CD4 cell counts (IQR) cells $/ \mathrm{mm}^{3}$ & $406.5(293,600)$ & $448(299,620)$ & 0.83 \\
\hline $\begin{array}{l}\text { Proportion of subjects with undetectable } \\
\text { plasma HIV-RNA }(\%)(\mathrm{N}=76)\end{array}$ & 19 (82.6) & $48(90.6)$ & 0.43 \\
\hline
\end{tabular}


Table 2. Psychosocial factors in studied patients according to Cognitive Behavioral Therapy condition.

\begin{tabular}{cccc}
\hline Psychological factors & $\begin{array}{c}\text { CBT group } \\
(\mathrm{n}=40)\end{array}$ & $\begin{array}{c}\text { Non-CBT group } \\
(\mathrm{n}=80)\end{array}$ & p-value $^{\dagger}$ \\
\hline Life stress event (\%) & & & 0.01 \\
Low level & $2(5.0)$ & $11(13.8)$ & \\
Average level & $29(72.5)$ & $65(81.3)$ & \\
High level & $9(22.5)$ & $4(5.0)$ & 0.06 \\
Social support (\%) & & & \\
Low level & $3(7.5)$ & $49(21.3)$ & \\
Average level & $33(82.5)$ & $14(17.5)$ & 1.00 \\
High level & $4(10.0)$ & $66(82.5)$ & \\
Mild Cognitive Impairment (\%) & $33(82.5)$ &
\end{tabular}

${ }^{\dagger} \mathrm{P}$-value base on Chi-square test for categorical variables.

Table 3. TDI scores in adult HIV-infected patients at baseline, immediately post-treatment and 3 months follow-up.

\begin{tabular}{|c|c|c|c|c|}
\hline & CBT group & Non-CBT group & Mean difference & $95 \% \mathrm{CI}$ \\
\hline Baseline & $(n=40)$ & $(n=80)$ & & \\
\hline :Mean TDI score (SD) & $26.70(4.87)$ & $25.28(4.83)$ & 1.42 & $-0.43,3.28$ \\
\hline Immediately post-treatment & $(n=40)$ & $(n=78)$ & & \\
\hline : Mean TDI score (SD) & $11.15(7.10)$ & $21.68(7.00)$ & & \\
\hline $\begin{array}{l}\text { :Mean change of TDI total } \\
\text { score from baseline(SD) }\end{array}$ & $15.55(6.47)$ & $3.54(4.57)$ & 12.01 & $9.98-14.05$ \\
\hline 3 months follow-up & $(n=38)$ & $(\mathrm{n}=70)$ & & \\
\hline :Mean TDI score (SD) & $7.89(6.01)$ & $22.51(6.66)$ & & \\
\hline $\begin{array}{l}\text { :Mean change of TDI total } \\
\text { score from baseline (SD) }\end{array}$ & $18.92(6.50)$ & $2.99(4.65)$ & 15.93 & $13.55-18.32$ \\
\hline
\end{tabular}

CBT = Cognitive Behavioral Therapy TD I = Thai Depression Inventory

$<0.001)$.

From univariate analysis, to compare baseline characteristics between CBT versus non-CBT group, we found that there were statistically significant higher score of life stress event in the CBT group ( $<<0.05)$. In addition, from literature review, age [35], gender [36], life stress event [37] and social support [38] were associated with depression. Therefore, regarding multivariate analysis, we selected these variables and incorporated into the linear regression model to control for confounding effects. The result revealed statistically significant association between CBT and changes of depression both immediately and at 3-month post-treatment as shown in Table 4. These finding supported that the effect of CBT for treatment of depression among HIV-infected patients was sustained over time after treatment.

\section{Disscussion}

Our study found that CBT was associated with changes in depression score both immediately and at 3-month post-treatment. These findings were consistent with several studies in western countries which demonstrated the efficacy of CBT for HIV-infected patients with depression in diverse populations [15,33,39-41]. In addition, our study demonstrated that, immediately and 3-month post-treatment, the mean TDI score among patients in the CBT group decreased substantially from the baseline. These changes in TDI score were more profound than other studies. Kelly et al. [42], found that the mean change of depression score in CBT group was 6.2 immediately and 3.2 at 3-month poat-treatment. In Thailand, CBT has been used for treatment of depression in non HIV-infected patients. It was tailored to suit the Thai cultural context based on Buddhism for addressing spiritual aspect combined with therapeutic techniques most applicable for group of patients who have some stigmatization. CBT has several techniques to alleviate depression [43] especially cognitive restructuring and active coping style [24,44]. Consequently, these techniques resulted in high retention and adherence to treatment instruction among patients. Previous studies showed that participation in homework assignments in CBT group treatment was associated with improved outcomes $[45,46]$. In addition, several studies found that therapist could be effective treatment deliverer [3,24]. The therapist will focus on the patient's difficulty and problems with empathy, encourage other group members by asking to support and share their ideas in the process. CBT modules are made to approach in each treatment session. The first module, Psycho-education, informs about depressive symptoms, using motivational interviewing to help clients change their hopeless cognition by asking the clients finding someone or something to make their hopeness and worthness for the rest of their life, collaboratively sets an agenda for the session, introduction to CBT for depression and also teach them to understand 
Table 4. Adjusted mean difference of depression scores between CBT group and non-CBT group at immediately post-treatment and 3-month post-treatment from baseline.

\begin{tabular}{lcc}
\hline \multicolumn{1}{c}{ CBT } & Mean difference $^{\dagger}$ & 95\% CI \\
\hline Immediately post-treatment & 12.13 & $10.00-14.26$ \\
3 months follow-up period & 15.94 & $13.69-18.18$ \\
\hline
\end{tabular}

${ }^{\dagger}$ Adjusted for age, gender, social support and life stress event.

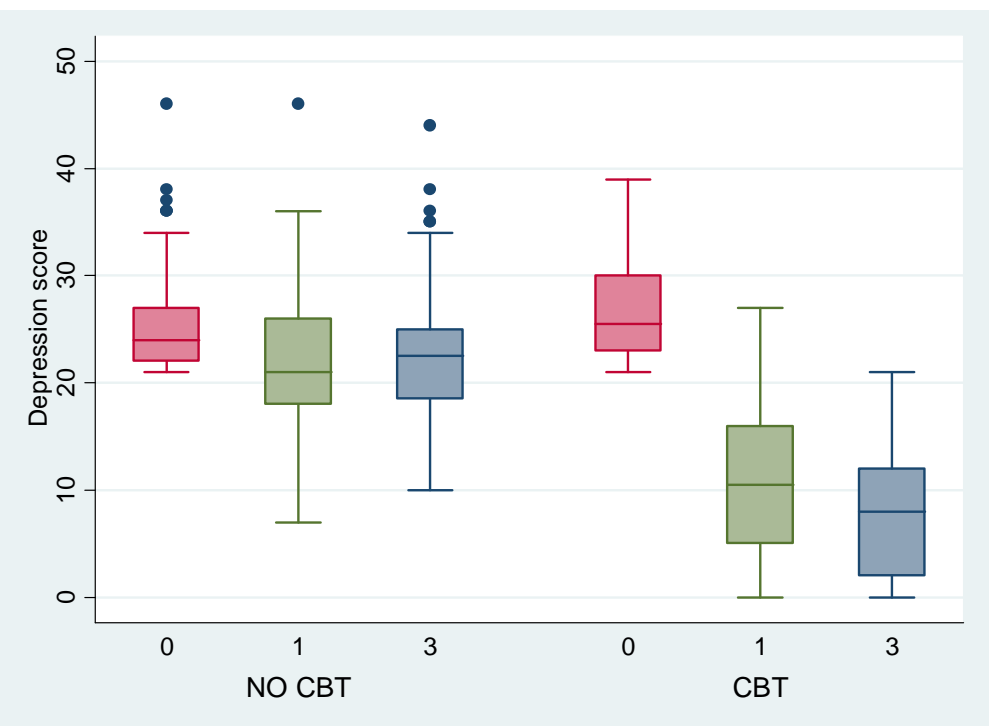

Figure 2. Depression scores of CBT group and comparison group at baseline, immediately post-treatment and 3-month post-treatment.

the pattern of relation between situation, automatic thought and emotion, behavior and physiology. The second module, relaxation training which consist of progressive muscle relaxation training and diaphragmatic breathing skills, is widely used in behavioral medicine to teach clients learning about relaxing during stress times. Next, Activity scheduling module focuses on behavioral activation occurring pleasure and mastery and teach them to monitoring life style in each day maximizing activities that makes clients feel better or under-represented utilize activities. The forth module is cognitive restructuring starting from teaching clients to identify negative automatic thoughts that contribute to negative emotions and maladaptive behaviors. It also evaluates thoughts based on the evidence such as information and facts but not interpretations and opinions, modify their dysfunctional thoughts and then facilitate them to learn adaptive coping skills by problem solving module [47]. The problem solving module uses problem-solving steps which consist of defining the problem that causes depression, generate alternative solutions, evaluates the alternatives by weighing up pros and cons, makes decisions about the alternatives, and finally, makes a plan about how to implement solutions [48]. However, in our study the subjects in CBT group had voluntarily participated, they tend to adhere to the treatment and resulted in high retention rate. This might be another reason for high retention rate in the CBT group in our study. In Thailand, the stigmatization is a major social problem among HIVinfected patients which may contribute to depression. Some responses from patients' interview in our study indicated that provision of social support through group sharing was valuable in alleviate their depression by changing the pattern of thought that they were not ones with stigmatized and serious chronic illness especially patients who were often isolated from family members, friends or relatives.

The results of our study indicated the benefit of CBT in treatment of depression in $\mathrm{HIV}$-infected patients. Therefore, CBT should be implemented as a routine part of standard of care in order to integrate psychosocial treatment dimension into holistic care and improve quality of life of patients in the long term. However our study was based on the study population from tertiary care hospital. Further study of CBT treatment in community-based practice should be done to provide more feasibility, availability, and accessibility for patients. In addition, cost-effectiveness analysis of CBT for treatment of HIV-infected patients with depression is suggested.

In our study, some patients felt inconvenient to attend 
the CBT courses in the hospital due to the problem of transportation. Previous study showed that the CBT could be applied by telephone-administration [49]. Therefore further study about telephone-administered CBT should be conducted in Thailand. Because it has been shown that depression was associated with adherence to HAART [3,10-14], future research to explore the association between improvement of depression by CBT and adherence to HAART regimens and immune function of HIV-infected patients should be conducted.

The strength of our study was that we focused on changes of depression both immediately and over time after treatment with CBT. We also examined the prevention of relapse of depression and found that the effect of CBT was sustained at 3-month post-treatment. Moreover, we used the multiple linear regression model to control the potential confounding effects.

The present study had some limitations. The analysis was based on the cohort study. Though we used the multivariate analysis to adjust for known potential confounding variables, we could not control the effects from other unknown variables. Therefore, a randomized controlled trial should be further conducted. Because subjects in the CBT group were recruited voluntarily the selection bias might occur. This also raised a possibility of information bias.

Although this study was designed to examine the sustainable effect of CBT, we only followed up the subjects for 3 months after treatment. This follow-up time might be too short to demonstrate the sustainability of CBT. Further study to assess changing of depression for longer period after treatment, such as 6 months and 12 months, should be done. The result of longer period study might be helpful to answer the question about prevention of relapse of depression by using the CBT.

\section{Acknowledgements}

This study was supported by The $90^{\text {th }}$ Anniversary of Chulalongkorn University Fund (Ratchadapiseksomphot Endowment Fund). The authors would like to thank all the personnel at sexually transmitted diseases clinic and immunology clinic, King Chulalongkorn Memorial Hospital for their kind assistance.

\section{REFERENCES}

[1] World Health Organization, “Depression,” 2011. http://www.who.int/mental_health/mamagement/depressi on/definition/en/.

[2] A. F. Angelino and G. J. Treisman, "Management of Psychiatric Disorders in Patients Infected with Human Immunodeficiency Virus," Clinical Infectious Disease, Vol. 33, No. 6, September 2001, pp. 847-856.

\section{doi:10.1086/322679}

[3] N. Crepaz, W. F. Passin, J. H. Herbst, S. M. Rama, R. M. Malow, D. W. Purcell, et al., "Meta-Analysis of Cognitive-Behavioral Interventions on HIV-Positive Persons' Mental Health and Immune Functioning," Health Psychology, Vol. 27, No. 1, 2008, pp. 4-14. doi:10.1037/0278-6133.27.1.4

[4] P. Tangtulyankul and T. Nilchaikovit, "Anxiety and Depression in Patients with HIV/AIDS," Proceedings of Final Program and Abstracts 6th Congress of Asean Federation for Psychiatry and Mental Health \& 10th Asean Forum on Child and Adolescent Psychiatry, Bangkok, November 1996, p. 50.

[5] S. Reungtrakul, “Acquired Immunodeficiency Syndrome: A Psychiatric Symptoms and Therapy,” Ruankhaw Press, 2005.

[6] C. Zilber, "Psychotherapeutic Strategies,” In: F. Fernandez, Ed., Psychiatric Aspects of HIVIAIDS, Lippincott Williams \& Wilkins, Philadelphia, 2006, pp. 355-364.

[7] R. Rabkin and J. G. Rabkin, "Management of Depression in Patients with Hiv Infection," In: W. Odets, Ed., The Second Decade of Aids: A Mental Health Practice Handbook, Hatherleigh Press, New York, 1995, pp. 1-25.

[8] L. Cheever, "What Do We Know about Adherence Levels in Different Populations?” Proceedings of HRSA, the Forum for Collaborative HIV Research and NIH of AIDS Research Workshop of Adherence to HIV Therapy: Building a Bridge to Success, Washington DC, November 1999, p. 9.

[9] J. Leserman, G. Ironson, C. O’Cleirigh, J. M. Fordiani and E. Balbin, "Stressful Life Events and Adherence in HIV,” AIDS Patient Care and STDs, Vol. 22, No. 5, 2008, pp. 403-411. doi:10.1089/apc.2007.0175

[10] V. Gordillo, J. D. Amo, V. Soriano and J. GonzalezLahoz, "Sociodemographic and Psychological Variables Influencing Adherence to Antiretroviral Therapy," AIDS, Vol. 13, No. 13, May 1999, pp. 1763-1769. doi:10.1097/00002030-199909100-00021

[11] S. L. Catz, J. A. Kelly, L. M. Bogart, E. G. Benotsch and T. L. McAuliffe, "Patterns, Correlates, and Barriers to Medication Adherence among Persons Prescribed New Treatments for HIV Disease,” Health Psychology, Vol. 19, No. 2, March 2000, pp. 124-133. doi:10.1037/0278-6133.19.2.124

[12] S. R. Penzak, Y. S. Reddy and S. R. Grimsley, "Depression in Patients with HIV Infection," American Journal of Health-System Pharmacists, Vol. 57, No. 4, February 2000, pp. 376-386.

[13] N. Buathong, N. Hiransuthikul, S. Tangwongchai and C. Komoltri, "Association between Depression and Adherence to Highly Active Antiretroviral Therapy among Adult HIV Infected Patients in Thailand," Asian Biomedicine, Vol. 3, 2009, pp.1-7.

[14] J. A. Bartlett, "Addressing the Challenges of Adherence," Journal of Acquired Immune Deficiency Syndromes, Vol. 29, No. 2 (Supplement), 2002, pp. S2-10. 
doi:10.1097/00126334-200202011-00002

[15] P. Williams, L. Narciso, G. Browne, J. Roberts, R. Weir and A. Gafni, "The Prevalence, Correlates, and Costs of Depression in People Living with HIV/AIDS in Ontario: Implications for Service Directions," AIDS Education and Prevention, Vol. 17, No. 2, 2005, pp. 119-130. doi:10.1521/aeap.17.3.119.62903

[16] J. D. Hartzell, I. E. Janke and A. C. Weintrob, "Impact of Depression on HIV Outcomes in the HAART Era," Journal of Antimicrobial Chemotherapy, Vol. 62, No. 2, 2008, pp. 1-10.

[17] C. D. Sherbourne, R. D. Hays, J. A. Fleishman, B. Vitiello, K. M. Magruder, E. G. Bing, et al., "Impact of Psychiatric Conditions on Health-Related Quality of Life in Persons with HIV Infection," American Journal of Psychiatry, Vol. 157, No. 2, 2000, pp. 248-254. doi:10.1176/appi.ajp.157.2.248

[18] G. Ironson, C. O’Cleirigh, M. A. Fletcher, J. P. Laurenceau, E. Balbin, N. Klimas, et al., "Psychosocial Factors Predict CD4 and Viral Load Change in Men and Women with Human Immunodeficiency Virus in the Era of Highly Active Antiretroviral Treatment," Psychosomatic Medicine, Vol. 67, No. 6, 2005, pp. 1013-1021. doi:10.1097/01.psy.0000188569.58998.c8

[19] J. Leserman, J. M. Petitto, H. Gu, B. N. Gaynes, J. Barroso, R. N. Golden, et al., "Progression to AIDS, a Clinical AIDS Condition and Mortality: Psychosocial and Physiological Predictors," Psychological Medicine, Vol. 32, No. 6, 2002, pp. 1059-1073. doi:10.1017/S0033291702005949

[20] S. Himelhoch, D. R. Medoff and G. Oyeniyi, "Efficacy of Group Psychotherapy to Reduce Depressive Symptoms among HIV-Infected Individuals: A Systematic Review and Meta Analysis," AIDS Patient Care and STDs, Vol. 21, No. 10, 2007, pp. 732-739. doi:10.1089/apc.2007.0012

[21] L. J. Fulk, B. E. Kane, K. D. Phillips, C. M. Bopp and G. A. Hand, "Depression in HIV-Infected Patients: Allopathic, Complementary and Alternative Treatments," Journal of Psychosomatic Research, Vol. 57, No. 4, 2004, pp. 339-351. doi:10.1016/S0022-3999(04)00070-4

[22] J. E. Young, J. L. Rych, A. D. Weinberger and A. T. Beck, "Cognitive Therapy for Depression," In: D. H. Barlow, Ed., Clinical Handbook of Psychological Disorders: A Step-by-Step Treatment Manual, The Guilford Press, New York, 2008, pp. 250-305.

[23] P. DeRoche and K. Citron, "Psychotherapy,” In: K. Citron, Ed., HIV and Psychiatry: A Training and Resource Manual, Cambridge University Press, Cambridge, 2005, pp. 153-169. doi:10.1017/CBO9780511543586.010

[24] M. R. Lee, L. Cohen, S. W. Hadley and F. K. Goodwin, "Cognitive-Behavioral Group Therapy with Medication for Depressed Gay Men with Aids or Symptomatic HIV Infection,” Psychiatric Services, Vol. 50, No. 7, 1999, pp. 948-952.

[25] S. D. Maat, J. Dekker, R. Schoevers and F. D. Jonghe,
"Relative Efficacy of Psychotherapy and Pharmacotherapy in the Treatment of Depression: A Meta-Analysis," Psychotherapy Research, Vol. 16, No. 5, October 2006, pp. 566-578. doi:10.1080/10503300600756402

[26] L. A. Panther and H. Libman, "Medical Overview,” In: K. Citron, Ed., HIV and Psychiatry: A Training and Resource Manual, Cambridge University Press, Cambridge, 2005, pp. 1-29. doi:10.1017/CBO9780511543586.002

[27] J. S. Beck, "In Session with Judith S. Beck: Cognitive-Behavioral Therapy,” Primary Psychiatry, Vol. 13, No. 4, April 2006, pp. 31-34.

[28] A. T. Beck, "Cognitive Therapy of Depression,” Guilford Press, New York, 1979.

[29] D. D. Burns and S. N. Hoeksema, "Coping Styles, Homework Compliance and the Effectiveness of Cognitive-Behavioral Therapy," Journal of Consulting and Clinical Psychology, Vol. 59, No. 2, 1991, pp. 305-311. doi:10.1037/0022-006X.59.2.305

[30] M. Lotrakul and P. Sukanich, "Development of the Thai Depression Inventory," Journal of Medical Association of Thailand, Vol. 82, No. 12, 1999, pp. 1200-1207.

[31] Z. S. Nasreddine, N. A. Phillips and V. Bedirian, "The Montreal Cognitive Assessment (MoCA): A Screening Tool for Mild Cognitive Impairment," Journal of the American Geriatrics Society, Vol. 53, No. 4, April 2004, pp. 695-699. doi:10.1111/j.1532-5415.2005.53221.x

[32] S. Nakrapanich, "Life Events and Adaptation during Pregnancy of Women with and without Obstetric Complication in Chulalongkorn Hospital," Master of Science's Thesis, Chulalongkorn University, Bangkok, 1988.

[33] S. A. Safren, C. O’Cleirigh, J. Y. Tan, S. R. Raminani, L. C. Reilly, M. W. Otto, et al., "A Randomized Controlled Trial of Cognitive-Behavioral Therapy for Adherence and Depression (CBT-AD) in Hiv-Infected Individuals," Health Psychology, Vol. 28, No. 1, 2009, pp. 1-10. doi:10.1037/a0012715

[34] S. Lemeshow, D. W. Hosmer, J. Klar and S. K. Lwanga, "Adequacy of Sample Size in Health Studies," John Wiley\&Sons, New York, 1990.

[35] S. C. Kalichman, T. Heckman, A. Kochman, K. Sikkema and J. Bergholte, "Depression and Thoughts of Suicide among Middle-Aged and Older Persons Living with HIV-AIDS,” Psychiatric Services, Vol. 51, No. 7, 2000, pp. 903-907. doi:10.1176/appi.ps.51.7.903

[36] M. F. Morrison, J. M. Petitto, H. T. Ten, D. R. Gettes, M. S. Chiappini, A. L. Weber, et al., "Depressive and Anxiety Disorders in Women with HIV Infection," American Journal of Psychiatry, Vol. 159, No. 5, 2002, pp. 789-796. doi:10.1176/appi.ajp.159.5.789

[37] S. Crystal and R. C. Kersting, "Stress, Social Support, and Distress in a Statewide Population of Persons with AIDS in New Jersey," Social Work in Health Care, Vol. 28, No. 1, 1998, pp. 41-60. doi:10.1300/J010v28n01 03

[38] W. Odets and M. Shernoff, "The Second Decade of AIDS: A Mental Health Practice Handbook,” Hatherleigh Press, New York, 1995. 
[39] A. Laperriere, G. H. Ironson, M. H. Antoni, H. Pomm, D. Jones, M. Ishii, et al., "Decreased Depression up to One Year Following CBSM + Intervention in Depressed Women with Aids: The Smart/EST Women's Project," Journal of Health Psychology, Vol. 10, No. 2, 2005, pp. 223-231. doi:10.1177/1359105305049772

[40] C. P. Kong, P. Leung, A. Au, P. Li, R. Chung, et al., "Cognitive-Behavioral Group Program for Chinese Heterosexual Hiv-Infected Men in Hong Kong,” Patient Education and Counseling, Vol. 56, 2005, pp. 78-84. doi:10.1016/j.pec.2003.12.010

[41] N. Soroudi, G. K. Perez, J. S. Gonzalez, J. A. Greer, M. H. Pollack, M. W. Otto, et al., "CBT for Medication Adherence and Depression (CBT-AD) in Hiv-Infected Patients Receiving Methadone Maintenance Therapy,” Cognitive and Behavioral Practice, Vol. 15, No. 1, 2008, pp. 93106. doi:10.1016/j.cbpra.2006.11.006

[42] J. A. Kelly, D. A. Murphy, R. Bahr, S. C. Kalichman, M. G. Morgan, Y. Stevenson, et al., "Outcome of Cognitive-Behavioral and Support Group Brief Therapies for Depressed, HIV-Infected Persons," American Journal of Psychiatry, Vol. 150, No. 11, 1993, pp. 1679-1686.

[43] J. S. Beck, "Cognitive Therapy: Basics and Beyond," Guilford Press, New York, 1995.

[44] S. K. Lutgendorf, M. H. Antoni, G. Ironson, K. Starr, N. Costello, M. Zuckerman, et al., "Changes in Cognitive Coping Skills and Social Support during Cognitive Be- havioral Stress Management Intervention and Distress Outcomes in Symptomatic Human Immunodeficiency virus (HIV)-Seropositive Gay Men,” Psychosomatic Medicine, Vol. 60, No. 2, 1998, pp. 204-214.

[45] N. Kazantzis, F. P. Deane and K. R. Ronan, "Homework Assignments in Cognitive and Behavioral Therapy: A Meta-Analysis," Clinical Psychology: Science and Practice, Vol. 7, No. 2, 2000, pp. 189-202. doi:10.1093/clipsy.7.2.189

[46] B. Haarhoff and N. Kazantzis, "How to Supervise the Use of Homework in Cognitive Behavior Therapy: The Role of Trainee Therapist Beliefs," Cognitive and Behavioral Practice, Vol. 14, No. 3, 2007, pp. 325-332. doi:10.1016/j.cbpra.2006.08.004

[47] Jayasvasti, “A Cognitive Behavioral Therapy Manual for HIV-Infected Patients with Depression: CBT-D for HIV-Infected Patients Treatment Manual,” Department of Preventive and Social Medicine, Faculty of Medicine, Chulalongkorn University, 2010.

[48] T. J. D'Zurilla and A. M. Nezu, "Problem-Solving Therapy: A Positive Approach to Clinical Intervention," Springer, New York, 2007.

[49] T. G. Heckman and B. Carlson, “A Randomized Clinic Trial of Two Telephone-Delivered, Mental Health Interventions for HIV-Infected Persons in Rural Areas of the United States,” AIDS and Behavior, Vol. 11, No. 1, 2007, pp. 5-14. doi:10.1007/s10461-006-9111-9 